\title{
Influence of a Ginkgo biloba extract on the binding of [F-18]-fluorodeoxyglucose (18F-FDG) on blood constituents
}

\author{
Luiz Cláudio Martins Aleixo ${ }^{1,2}$, Silvana Ramos Farias Moreno ${ }^{1,3}$, Rosimeire de Souza Freitas ${ }^{1}$, \\ Gláucio Feliciano Diré ${ }^{1,4}$, Sebastião David Santos-Filho', and Mario Bernardo-Filho ${ }^{1,5}$ \\ ${ }^{1}$ Universidade do Estado do Rio de Janeiro, Instituto de Biologia Roberto Alcântara Gomes, Departamento de Biofísica \\ e Biometria, 28 de Setembro, 87, 20551-030, Rio de Janeiro, RJ, Brasil. \\ ${ }^{2}$ Comissão Nacional de Energia Nuclear, Instituto de Engenharia Nuclear, Cidade Universitária, llha do Fundão, Via \\ Cinco s/n, 21945-450 Rio de Janeiro, Brasil. \\ ${ }^{3}$ Departamento de Patologia, Universidade Federal Fluminense, 24030-210, Niterói, RJ, Brasil. \\ ${ }^{4}$ Departamento de Neurofarmacologia, Universidade Estadual da Zona Oeste, Rio de Janeiro. \\ ${ }^{5}$ Instituto Nacional do Câncer, Praça da Cruz Vermelha, 23, 20230-130 Rio de Janeiro, Brasil.
}

Accepted 4 June, 2013

\begin{abstract}
Radiopharmaceuticals are used in procedures of nuclear medicine for the diagnosis and treatment of illnesses. Fluorine-18 $\left({ }^{18} \mathrm{~F}\right)$ is a positron emitter produced in cyclotron. It is used to get ${ }^{18}$ fluorodeoxyglucose $\left({ }^{18} \mathrm{~F}-\mathrm{FDG}\right)$ that is a radiopharmaceutical utilized in the positron emission tomography scan. The aim of this work was to evaluate the in vitro effect of an extract of Ginkgo biloba extract $(E G b)$ on the distribution in blood cells $(B C)$ and plasma $(P)$ compartments and on the binding to the blood constituents of the ${ }^{18}$ F-FDG using precipitation with trichloroacetic acid (TCA). EGb was not capable to interfere on the distribution of the ${ }^{18} \mathrm{~F}-\mathrm{FDG}$ on the $\mathrm{BC}$ and $\mathrm{P}$ compartments. However, this extract was capable of interfering significantly $(p<0.05)$ on the fixation of the ${ }^{18} F-F D G$ on IF-P (in all the concentrations tested, $P<0.05$ ) and IF-BC in $1 \%$ TCA concentration from $14.04 \pm 1.13$ to $10.23 \pm 1.92$ $(40 \mathrm{mg} / \mathrm{ml}, \mathrm{EGb})$ and to $9.35 \pm 1.57(400 \mathrm{mg} / \mathrm{ml} / \mathrm{EGb})$, in $5 \% \mathrm{TCA}$ concentration from $14.83 \pm 3.78$ to $11.15 \pm 1.64(40 \mathrm{mg} / \mathrm{ml}, \mathrm{EGb})$ and to $10.23 \pm 1.6(400 \mathrm{mg} / \mathrm{ml}, \mathrm{EGb})$. In conclusion, the analysis of the results indicates that the EGb was not capable to interfere on the distribution of the ${ }^{18} \mathrm{~F}-\mathrm{FDG}$ on $\mathrm{P}$ and $\mathrm{BC}$ compartments, however, alter the fixation of the 18FDG on IF-P and IF-BC.
\end{abstract}

Key words: ${ }^{18}$ Fluorodeoxyglucose, blood compartments, radiopharmaceutical, Ginkgo biloba, medicinal plants.

\section{INTRODUCTION}

Radiopharmaceuticals or radiobiocomplexes are employed in nuclear medicine for diagnostic and/or treatment of diseases or to study blood flow, morphology of organs, bioavailability and metabolism of drugs (Saha, 2010). An important step to understand the mechanism of localization of radiopharmaceuticals in a specific target, as well as they are cleared from blood or eliminated from the body or the rate at which their excretions occur, it is 
the determination of their binding to the blood proteins. The secure determination of the binding of radiopharmaceuticals to the plasma $(\mathrm{P})$ and blood cell $(\mathrm{BC})$ constituents can aid to understand the interference of various conditions on the distribution of radiopharmaceuticals in the body (Saha, 2010). To investigate the radiobiocomplexes-protein binding, these complexes of protein-bound-radiobiocomplex must be separated from the free radiobiocomplex. This has been accomplished by precipitation of the proteins with precipitating agents, as trichloroacetic acid (TCA) (Freitas et al., 2007) or ethanol (Fernandes et al., 2007).

Fluorine-18 $\left({ }^{18} \mathrm{~F}\right)$ is the positron emitter radionuclide (half life of 109.77 minutes) produced in cyclotron mostly used to positron emission tomography (PET) scan. It is utilized to get ${ }^{18}$ fluorodeoxyglucose $\left({ }^{18} \mathrm{~F}-\mathrm{FDG}\right)$, that is a radiolabeled glucose analogue (Aus et al., 2005; Saha, 2010; Velasques de Oliveira et al., 2010a). ${ }^{18}$ FDG-PET provides insight into the biological behavior of tumors rather than their morphological appearance (Velasques de Oliveira et al., 2010b). PET is useful to determine in vivo physiological and biochemical processes of noninvasive character (Phelps, 2000). PET can target several biological features of tumors including glucose metabolism, cell proliferation, tissue perfusion, and hypoxia (Rohren et al., 2004; Zhang et al., 2007). Following malignant transformation, a range of tumors can be characterized by elevated glucose consumption and subsequent increased uptake of the radiolabeled glucose analogue FDG (Rohren et al., 2004; Zhang et al., 2007).

Normal distribution of ${ }^{18} \mathrm{~F}$-FDG includes high uptake in the brain, in the kidneys and bladder because of renal clearance (Jager, 2005). Some authors have already reported that in mice, dogs, and man, the ${ }^{18} \mathrm{~F}-\mathrm{FDG}$ clears from the other organs and it is excreted to a large extent in the urine. Reymond et al. (2007) have observed that the ${ }^{18}$ F-FDG on the blood decreases rapidly with the time.

Jeghers et al. (1990) have reported that the reversible and non-reversible interactions of small molecules with macromolecules, such as proteins. These bindings can interfere with the bioavailability, the rate of elimination, the access to the action site/target, and with the metabolism (Jeghers et al., 1990). Moreover, authors have pointed out that in nuclear medicine, it is essential the understanding and quantification of this phenomenon in order to anticipate the behavior in vivo of radiotracers (Velasques de Oliveira et al., 2010b). In addition, authors have reported that several synthetic (Nigri et al., 2002) and natural medications (Moreno et al., 2007; Moreno et al., 2008a; Moreno et al., 2008b; Moreno et al., 2008c; Souza et al., 2011) are capable of interfering with the biodistribution and/or on the radiolabeling of blood constituents. These considerations show the importance of the studies about the effect of medications on the behavior of the radiopharmaceuticals. This fact has an additional importance if the natural medications are considered, due to the consumption of natural products, as food, additives or medication, has been growing all over the world (Simões et al., 2007; Steenkamp et al., 2013).

Ginkgo biloba extract (EGb) is a medicinal herb, which comes from leaves of the ginkgo tree, one of the oldest living plant species (Simões et al., 2007). This extract has several effects, including, increases the blood flow, acts as platelet activating factor antagonism and prevents the membrane against the damage caused by free radicals (Simões et al., 2007). Moreover, EGb scavenges free radicals such as hydroxyl radicals and superoxide anions (Moreno et al., 2004; Simões et al., 2007). The redox properties of this extract are probably due to the presence of the flavonoids (Moreno et al., 2004). Considering the publications in the PubMed (http//: wwwnobi.nlm.nih.gov/sites/entrez, at april 18, 2013) there are no references on the effect of natural drugs on the fixation of ${ }^{18} \mathrm{~F}$-FDG on blood constituents, and this fact has stimulated the evaluation of the effect in vitro of a $G$. biloba extract on the distribution of the ${ }^{18} \mathrm{~F}$-FDG on the blood compartments (plasma and blood cells) and on the blood proteins (plasma and cellular) with TCA.

\section{MATERIALS AND METHODS}

\section{Ethical guidelines}

All the experimental procedures followed the Ethical Guidelines of the Instituto de Biologia Roberto Alcantara Gomes, Universidade do Estado do Rio de Janeiro with the protocol number CEA/129/2006. The experiments were carried out with heparinized whole blood withdrawn from Wistar rats (male, 3 months of age, about $300 \mathrm{~g}$ ).

\section{Radiopharmaceutical production}

${ }^{18} \mathrm{~F}-\mathrm{FDG}$ was obtained through the synthesis module Tracer Lab MX of GE Medical System, Benelux SA-Belgium. The production and all the controls were performed by the the Departamento de Radiofarmácia, Instituto de Engenharia Nuclear, Comissão Nacional de Energia Nuclear, Rio de Janeiro, Brazil.

\section{Preparation of the extract}

An aqueous extract was prepared mixing 4 gram of $G$. biloba (Herbarium Laboratório Botânico LTDA, lot number 535036) in 10 $\mathrm{ml}$ of $0.9 \% \mathrm{NaCl}$ (saline). The mixture was centrifuged (clinical centrifuge, $1500 \mathrm{rpm}, 5 \mathrm{~min}$ ). The supernatant was considered to be $400 \mathrm{mg} / \mathrm{ml}$ and denominated $100 \%$ solution. Dilutions were performed with saline that was also used as a control. A spectrophotometric analysis (Analyser, $800 \mathrm{M}$, São Paulo, Brazil) of the undiluted extract was carried out and the absorbance was determined to each $20 \mathrm{~nm}$ in the range 400-700 nm. The absorbance at $440 \mathrm{~nm}$ was considered the marker of the quality control of preparation of this extract. All the prepared extracts to be used in the experiments must have the optical density of 0.162 (Figure 1). 


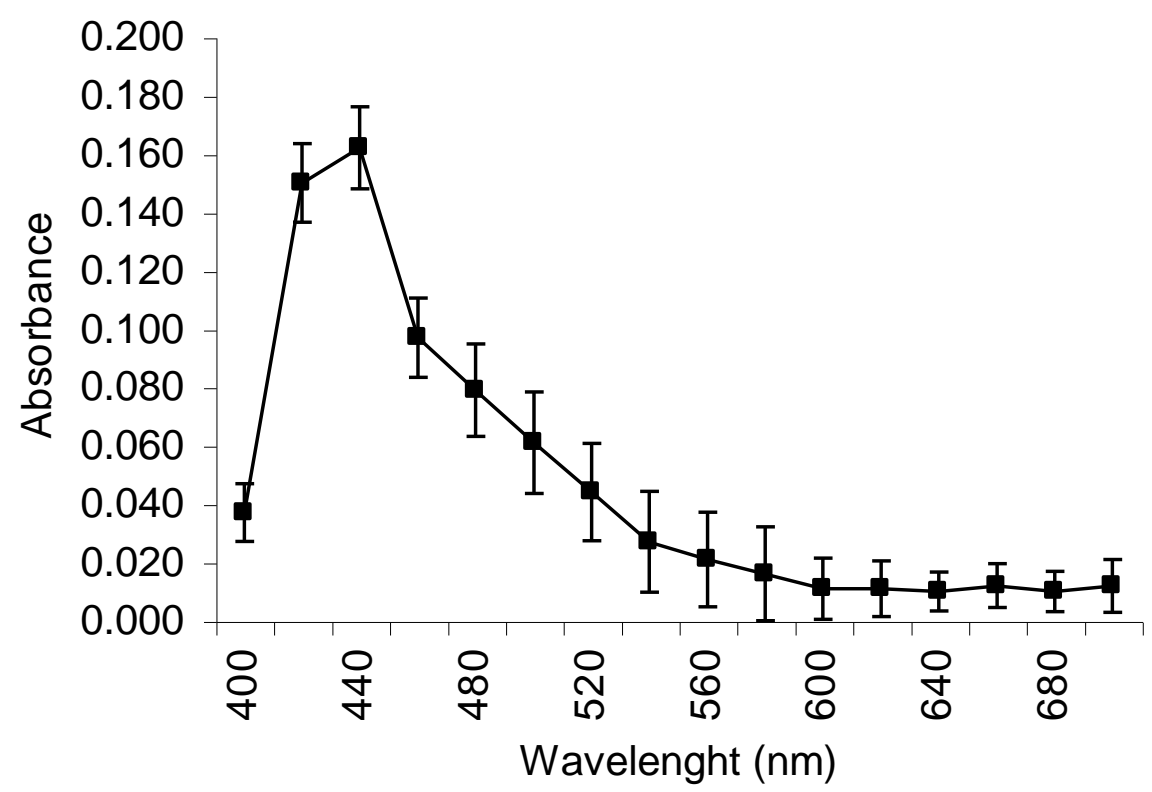

Figure 1. Absorption spectrum of the extracts of Ginkgo biloba used in the experiments. The pattern of the absorption spectrum of the extracts of Ginkgo biloba used in the experiments. It presents the highest measure of the optical density $(0.162$ \pm 0.014 ) at $440 \mathrm{~nm}$. This condition has permitted to control the conditions to prepare the extracts and has been used as a marker.

\section{Protein-binding}

Fresh anticoagulated whole blood $(3 \mathrm{ml})$ was incubated for $1 \mathrm{~h}$ with $300 \mu \mathrm{l}$ of the $\mathrm{G}$. biloba extract solution in the concentrations of 40 or $400 \mathrm{mg} / \mathrm{ml}$ at room temperature. $\mathrm{NaCl} 0.9 \%$ was used as control. After that, $100 \mu \mathrm{l}$ of ${ }^{18} \mathrm{~F}-\mathrm{FDG}(3.7 \mathrm{MBq})$ was added and incubated for more $20 \mathrm{~min}$. Blood preparations were centrifuged and plasma (P) and blood cells $(B C)$ were isolated. Aliquots $(25 \mu \mathrm{l})$ of $P$ and $B C$ were also precipitated with $1 \mathrm{ml}$ of freshly prepared solution of TCA in various concentrations $(0.1,0.5,1.0,5.0,10.0$ and $20.0 \%)$. In this condition, soluble (SF) and insoluble (IF) fractions from plasma and blood cells were separated. All samples, (P, BC, IF-P, SF-P, IF-BC and SF-BC) were counted in a well counter with $\mathrm{Nal}(\mathrm{TI})$ crystal (Clinigamma, gamma counter, Packard Instrument Company, mod C5002, USA).

\section{Percentage of radioactivity determination}

The percentage of radioactivity (\%ATI) (i) in $\mathrm{P}$ was determined dividing the counts in $P$ by sum of the counts in $P$ plus $B C$, (ii) in $B C$ was determined dividing the counts in $P$ by sum of the counts in $P$ plus $B C$, (iii) in IF-P was determined dividing the counts in IF-P by the sum of the counts in IF-P plus SF-P and (iv) in IF-BC was determined dividing the counts in IF-BC by the sum of the counts in IF-BC plus SF-BC. The values found were multiplied by 100 . The values are mean of 5 isolated experiments.

\section{Statistical analysis}

Statistical analysis (ANOVA test, with significance level $P<0.05, n=$ 5 ) was utilized to compare the \%ATI of radiopharmaceutical in the blood constituents and the various TCA concentrations.

\section{RESULTS AND DISCUSSION}

Figure 1 shows the pattern of the absorption spectrum of an EGb used in the experiments. It presented the highest measure of the optical density $(0.162 \pm 0.014)$ at $440 \mathrm{~nm}$. This condition has permitted to control the conditions to prepare the extracts used in the assays and it was used as a marker.

Table 1 shows the distribution of the ${ }^{18} \mathrm{~F}-\mathrm{FDG}$ on plasma and cellular compartment of the whole blood from Wistar rats that were incubated with the G. biloba extract. The \%ATI for ${ }^{18} \mathrm{~F}$-FDG was found mainly in the plasma compartment. This extract, in the two concentrations, was not capable to alter distribution of the ${ }^{18} \mathrm{~F}-\mathrm{FDG}$ in both compartments. Table 2 shows the fixation of the radioactivity in insoluble fractions obtained from plasma (IF-P) samples precipitated with different TCA concentrations. These samples of plasma were obtained from whole blood incubated with ${ }^{18} \mathrm{~F}-\mathrm{FDG}$ and with an EGb or saline. The extract, in the two used concentrations (40 and $400 \mathrm{mg} / \mathrm{ml}$ ), was capable to increase the fixation of the ${ }^{18} \mathrm{~F}-\mathrm{FDG}$ in the IF-P. The fixation of the radioactivity in IF-P in the control, in general, has increased with the concentration of TCA used. The \% of radioactivity that was found in the IF-P with the various TCA concentrations from whole blood treated with the G. biloba 
Table 1. Distribution of the radioactivity of the ${ }^{18} \mathrm{~F}-\mathrm{FDG}$ in the plasma and cellular compartment of the blood from Wistar rats treated with $G$. biloba extract.

\begin{tabular}{lll}
\hline Samples & Cellular compartment & Plasma compartment \\
\hline${ }^{18} \mathrm{~F}-\mathrm{FDG}$ (control) & $16.83 \pm 4.92$ & $83.17 \pm 4.92$ \\
${ }^{18} \mathrm{~F}-\mathrm{FDG}+$ extract $40 \mathrm{mg} / \mathrm{ml}$ & $15.32 \pm 3.18$ & $84.68 \pm 3.18$ \\
${ }^{18} \mathrm{~F}-\mathrm{FDG}+$ extract $400 \mathrm{mg} / \mathrm{ml}$ & $17.61 \pm 2.91$ & $82.39 \pm 2.91$ \\
\hline
\end{tabular}

Fresh whole blood $(3 \mathrm{ml}$ ) was incubated for $1 \mathrm{~h}$ with $300 \mu \mathrm{l}$ of the vegetable extract of $\mathrm{G}$. biloba in the concentrations of 40 and $400 \mathrm{mg} / \mathrm{ml}$. NaCl $0.9 \%$ was used as control. After incubation $100 \mu \mathrm{l}$ of ${ }^{18} \mathrm{~F}$-FDG $(100 \mu \mathrm{Ci} ; 3.7 \mathrm{MBq})$ was added and incubated for additional $20 \mathrm{~min}$. After that, the blood preparations were centrifuged and plasma $(P)$ and blood cells (BC) were isolated. Statistical analysis with ANOVA test, significance level $P<0.05, n=5$, was utilized. Note that the difference between the \%ATI of treated samples with the extract (40 and $400 \mathrm{mg} / \mathrm{mL}$ ) and controls is not significant $(p>0.05)$.

Table 2. Distribution of the radioactivity of the ${ }^{18} \mathrm{~F}-\mathrm{FDG}$ in the plasma (IF-P) of the blood from Wistar rats treated with Ginkgo biloba extract.

\begin{tabular}{|c|c|c|c|}
\hline \multirow[b]{2}{*}{$\begin{array}{l}\text { TCA } \\
\text { concentration (\%) }\end{array}$} & \multirow[b]{2}{*}{$\begin{array}{l}\text { Control } \\
\text { (Mean } \pm \text { S.D.) }\end{array}$} & \multicolumn{2}{|c|}{ Insoluble fraction (Mean \pm S.D.) } \\
\hline & & $\begin{array}{l}\text { Extract concentration } \\
(40 \mathrm{mg} / \mathrm{ml})\end{array}$ & $\begin{array}{l}\text { Extract concentration } \\
(400 \mathrm{mg} / \mathrm{ml})\end{array}$ \\
\hline 0.1 & $2.29 \pm 1.15$ & $6.23 \pm 1.08^{*}$ & $5.32 \pm 0.94^{*}$ \\
\hline 0.5 & $1.92 \pm 0.68$ & $5.12 \pm 0.91^{*}$ & $4.26 \pm 1.23^{*}$ \\
\hline 1.0 & $1.98 \pm 0.48$ & $4.89 \pm 1.11^{*}$ & $4.11 \pm 0.82^{*}$ \\
\hline 5.0 & $2.16 \pm 0.41$ & $5.23 \pm 0.62^{*}$ & $5.01 \pm 1.30^{*}$ \\
\hline 10.0 & $2.72 \pm 1.01$ & $5.04 \pm 0.92^{*}$ & $4.12 \pm 0.93^{*}$ \\
\hline 20.0 & $3.92 \pm 0.44$ & $6.09 \pm 0.73^{*}$ & $5.75 \pm 0.89^{*}$ \\
\hline
\end{tabular}

Fresh whole blood $(3 \mathrm{ml})$ was incubated for $1 \mathrm{~h}$ with $300 \mu \mathrm{l}$ of the vegetable extract of $G$. biloba in the concentrations of 40 and $400 \mathrm{mg} / \mathrm{ml}$. NaCl $0.9 \%$ was used as control. After incubation $100 \mu \mathrm{l}$ of ${ }^{18} \mathrm{~F}$-FDG $(100 \mu \mathrm{Ci} ; 3.7 \mathrm{MBq})$ was added and incubated for more $20 \mathrm{~min}$. After that the blood preparations were centrifuged and plasma $(P)$ and blood cells $(B C)$ were isolated. Aliquots $(25 \mu \mathrm{l})$ of $\mathrm{P}$ and $\mathrm{BC}$ were also precipitated with $1 \mathrm{ml}$ of solution of trichloroacetic acid (TCA) in various concentrations $(0.1,0.5,1.0,5.0,10.0$ and $20.0 \%)$. Statistical analysis with ANOVA test, significance level $P<0.05, n=5$, was utilized. *Note that the difference between the \%ATI of treated samples with the extract ( 40 and $400 \mathrm{mg} / \mathrm{mL})$ and controls is significant $(p<0.05)$.

extract was statistically $(p<0.05)$ higher than in the control.

Table 3 shows the fixation of the radioactivity in insoluble fractions obtained from blood (IF-BC) samples precipitated with TCA concentrations. These samples of blood cells were obtained from whole blood that was incubated with ${ }^{18} \mathrm{~F}-\mathrm{FDG}$ and with an EGb or saline. It was observed that the fixation of the radioactivity in IF-BC in the control depends on the TCA concentration. The presence of the extract influenced the results and has statistically $(p<0.05)$ decreased the \%ATI on IF-BC in almost all the concentrations of the TCA.

The purpose of this investigation was to verify the action of an extract of $G$. biloba extract on the distribution of the ${ }^{18} \mathrm{~F}$-FDG on the blood constituents. Although the $E G b$ was not capable to interfere on the distribution of this radiopharmaceutical on the $\mathrm{BC}$ and $\mathrm{P}$ compartments, it was capable to interfere significantly $(p<0.05)$ on the fixation of the ${ }^{18} \mathrm{~F}-\mathrm{FDG}$ in IF-P and in IF-BC. These findings are worthwhile due to this interference might bring some complications in the interpretation of examinations done with ${ }^{18} \mathrm{~F}$-FDG patients that are using an extract of $G$. biloba. Our investigation with an extract of G. biloba is related to the fact that there is considerable evidence that the bioavailability of radiopharmaceuticals may be also altered by disease states, but also by a variety of drugs (natural and synthetic) (Bernardo-Filho et al., 2005). Moreover, the distribution of a radiopharmaceutical depends on its fixation on the blood constituents (Gano et al., 2009). If these factors are unknown, this fact may lead to the deficient visualization of organ, being necessary to repeat the procedure resulting in unnecessary exposure to the radiation or even misdiagnosis (Bernardo-Filho et al., 2005; Saha, 2010).

Authors have reported that the biodistribution, the rate of elimination, the access to the target organ and the metabolism depends on the interaction of the radiopharmaceutical with plasma proteins (Freitas et al., 2007). Although the introduction of ${ }^{18}$ F-FDG has provided a valuable tool for the study, the glucose metabolism in 
Table 3. Distribution of the radioactivity of the ${ }^{18} \mathrm{~F}-\mathrm{FDG}$ in the blood cell (IF-BC) of the blood from Wistar rats treated with G. biloba extract.

\begin{tabular}{|c|c|c|c|}
\hline \multirow[b]{2}{*}{$\begin{array}{l}\text { TCA } \\
\text { concentration (\%) }\end{array}$} & \multirow{2}{*}{$\begin{array}{l}\text { Control } \\
\text { (Mean } \pm \text { S.D.) }\end{array}$} & \multicolumn{2}{|c|}{ Insoluble fraction (Mean \pm S.D.) } \\
\hline & & $\begin{array}{ll}\text { Extract } & \text { concentration } \\
(40 \mathrm{mg} / \mathrm{ml}) & \\
\end{array}$ & $\begin{array}{l}\text { Extract concentration } \\
(400 \mathrm{mg} / \mathrm{ml})\end{array}$ \\
\hline 0.1 & $5.30 \pm 2.01$ & $5.17 \pm 1.51$ & $4.91 \pm 0.97$ \\
\hline 0.5 & $11.91 \pm 2.62$ & $9.25 \pm 1.37$ & $8.12 \pm 1.33$ \\
\hline 1.0 & $14.04 \pm 1.13$ & $10.23 \pm 1.92^{*}$ & $9.35 \pm 1.57^{*}$ \\
\hline 5.0 & $14.83 \pm 3.78$ & $11.15 \pm 1.64^{*}$ & $10.23 \pm 1.6^{*}$ \\
\hline 10.0 & $10.02 \pm 2.57$ & $10.36 \pm 1.71$ & $8.94 \pm 2.43$ \\
\hline 20.0 & $7.38 \pm 3.09$ & $6.25 \pm 1.39$ & $5.23 \pm 1.38$ \\
\hline
\end{tabular}

Fresh whole blood $(3 \mathrm{ml})$ was incubated for $1 \mathrm{~h}$ with $300 \mu \mathrm{l}$ of the vegetable extract of $G$. biloba in the concentrations of 40 and $400 \mathrm{mg} / \mathrm{ml}$. NaCl $0.9 \%$ was used as control. After incubation, $100 \mu \mathrm{l}$ of ${ }^{18} \mathrm{~F}$-FDG $(100 \mu \mathrm{Ci} ; 3.7 \mathrm{MBq})$ was added and incubated for additional $20 \mathrm{~min}$. After that, the blood preparations were centrifuged and plasma $(P)$ and blood cells $(B C)$ were isolated. Aliquots $(25 \mu \mathrm{l})$ of $\mathrm{P}$ and $\mathrm{BC}$ were also precipitated with $1 \mathrm{ml}$ of solution of trichloroacetic acid (TCA) in various concentrations $(0.1,0.5,1.0,5.0,10.0$ and 20.0\%). Statistical analysis with ANOVA test, significance level $P<0.05, n=5$, was utilized. *Note that the difference between the \%ATI of treated samples with the extract $(40$ and $400 \mathrm{mg} / \mathrm{mL})$ and controls is significant $(p<0.05)$.

normal and in disease tissue in conjunction with PET for brain, heart and tumors studies as well as research, there are no publications in the PubMed about studies of possible interactions of the ${ }^{18}$ F-FDG with natural drugs. The pharmacokinetic behavior of radiopharmaceuticals also depends on the fixation of the radiotracer on the blood proteins.

Moreover, a part of the radiopharmaceutical that reaches the blood is bound to the plasma proteins (Gano et al., 1989) and to blood proteins (Freitas et al., 2007). The central idea of this study is to verify if the EGb extract is capable to interfere in the fixation of the $18 \mathrm{~F}$ FDG in the IF-P and IF-BC due to the impact of this alteration on the bioavailability of the radiopharmaceutical and the undesirable consequences. It is known that the radiopharmaceutical uptake in organs may depend on its biochemical characteristics as well as the binding to blood constituents.

The correct determination of the binding of radioactivity on blood elements would be worthwhile for several reasons (i) to better understand how a drug is capable of modifying the biodistribution of radiopharmaceuticals, (ii) to evaluate the specific characteristics of the binding of each radiopharmaceutical to its targets in the blood, (iii) to avoid misdiagnosis, (iv) to avoid the repetition of examinations, ( $\mathrm{v}$ ) to avoid erroneous visualization and elucidation of the organ and (vi) to reduce the radiation dose to patients (Hladiklll et al., 1987; Santos-Oliveira and Machado, 2011).

According to Jeghers et al. (1990) are necessary new methods for the determination of protein binding for each class of radiopharmaceuticals (Jeghers et al., 1990). The findings obtained in this study indicated in Tables 1, 2 and 3 may aid to understand the rapid elimination of the ${ }^{18}$ F-FDG.

Some authors have demonstrated that the natural products G. biloba (Moreno et al., 2004), Uncaria tomentosa (Moreno et al., 2007) and Paullinia cupana (Freitas et al., 2007) are able to interfere with the labeling of red blood cells with ${ }^{99 \mathrm{~m}} \mathrm{Tc}$ and alter the fixation of the sodium pertechnetate to the precipitated blood proteins (plasma and cells proteins).

According to Aleixo et al. (2012), the extract of $G$. biloba interferes on the distribution of the sodium $\left[{ }^{123} \mid\right]$ iodide $\left(\mathrm{Na}^{123} \mathrm{I}\right)$ on the compartments as well as on the fixation on the plasma and blood cells proteins (Aleixo et al., 2012). The findings presented in Table 1 have revealed that $G$. biloba extract was not capable of interfering on the distribution of the ${ }^{18} \mathrm{~F}-\mathrm{FDG}$ in the plasma and cellular compartments. However, it was capable to interfere on the fixation of the ${ }^{18} \mathrm{~F}$-radio-pharmaceutical on the insoluble fraction obtained from plasma and cellular proteins (Tables 2 and 3 ) isolated from whole blood incubated with the $G$. biloba extract. It is possible to suggest that the chemical compounds present in $G$. biloba extract may alter these bindings, increasing or decreasing the radioactivity on the IF of the blood constituents.

In conclusion, as the biodistribution also depends on the fixation of the radiopharmaceuticals on the blood proteins and although, the experiments were carried out with animals, it is necessary to have precaution and to think about unexpected consequences in the bioavailability of the ${ }^{18} \mathrm{~F}-\mathrm{FDG}$ in patients that are undergoing $G$. biloba.

This conclusion is due to EGb altering the fixation of 
the ${ }^{18} \mathrm{~F}-\mathrm{FDG}$ on the blood proteins.

\section{ACKNOWLEDGMENTS}

The present work was carried out with support of the CNPq and FAPERJ. We are also indebted to UERJ and CNEN-IEN.

\section{ABBREVIATIONS}

${ }^{18}$ F-FDG, ${ }^{18}$ Fluorodeoxyglucose; P, plasma; BC, blood cell; IF, insoluble fraction; SF, Soluble fraction; TCA, thricloroacetic acid; PET, positron emission tomography; EGb, Ginkgo biloba extract.

\section{REFERENCES}

Aleixo LC, Moreno SRF, Freitas RS, Thomaz H, Santos-Filho SD, Bernardo-Filho M (2012). Ginkgo biloba extract alters the binding of the sodium $\left[{ }^{123} \mathrm{I}\right]$ iodide $\left(\mathrm{Na}^{123} \mathrm{I}\right)$ on blood constituents. Appl. Radiat. Isot. 70: 59-62.

Aus G, Abbou CC, Bolla M (2005). EAU guidelines on prostate cancer. Eur. Urol. 48: 546-51.

Bernardo-Filho M, Santos-filho SDE, Moura EG, Maiwarm AI, Orlando MMC, Penas ME (2005). Drug Interaction with radiopharmaceuticals: a Review. Braz. Arch. Biol. Technol. 28: 13-27.

Fernandes C, Kniess T, Gano L, Seifert S, Spies H, Santos I (2004). Synthesis and biological evaluation of silylated mixed-ligand $99 \mathrm{mTc}$ complexes with the [PNS/S] donor atom set. Nucl. Med. Biol. 31:78593.

Freitas RS, Moreno SFR, Lima-Filho GL, Fonseca AS, Bernardo-Filho $M$ (2007). Effect of a commercial extract of Paullinia cupana (guarana) on the binding of 99m Tc-DMSA on blood constituents: An in vivo study. Appl. Radiat. Isot. 65: 528-533.

Gano L, Patrício L, Castanheira I (1989). Radiopharmaceuticals for renal studies: evaluation of protein binding. J. Radioanal. Nucl. Chem. 132:171-178.

Hladik III, WB, Saha GB, Study KT (1987). Essentials of Nuclear Medicine Science. New York: Sidney, Williams and Wilkins.

Jager PL (2005). Molecular imaging: what can be used today. Can. Imag. 5:27-32.

Jeghers O, Piepsz A, Ham HR (1990). What does protein binding of radiopharmaceuticals mean exactly? Eur. J. Nucl. Med. 17:101-102.

Moreno SRF, Freitas RS, Rocha EK, Lima-Filho GL, Bernardo-Filho M (2004). Protection of plasmid DNA by Ginkgo biloba from the effects of stannous chloride and the action on the labeling of blood elements with technetium-99m. Braz. J. Med. Biol. Res. 37: 267-271.

Moreno SRF, Carvalho JJ, Rebello B, Rocha EK, Oliveira-Timóteo M, Olej B, Bernardo Filho M (2007). Effect of oral ingestion of an extract of the herb Uncaria tomentosa on the biodistribution of sodium pertechnetate in rats. Braz. J. Med. Biol. Res. 40: 77-80.
Moreno SRF, Carvalho JJ, Rebello B, Rocha EK, Oliveira-Timóteo M, Olej B, Bernardo Filho M (2008a). Experimental Models using Radionuclides for assessment effects of natural drugs. Braz. Arch. Biol. Technol. 51: 169-174.

Moreno S R F, Carvalho JJ, Rebello B, Rocha EK, Oliveira-Timóteo M, Olej B, Bernardo Filho M (2008b). Uncaria tomentosa extract: Evaluation of Effects on in vitro and in vivo Labeling of blood constituents with Technetium-99m and on the Survival of Escherichia coli. Braz. Arch. Biol. Technol. 51: 151-156.

Moreno S R F, Carvalho JJ, Rebello B, Rocha EK, Oliveira-Timóteo M, Olej B, Bernardo Filho M (2008c). Ultrastructural Analysis of kidney, liver and Duodenum isolated from treated rats with Ginkgo biloba extract and Effects of this medicinal plant on the biodistribution of the Radiopharmaceutical sodium pertechnetate. Braz. Arch. Biol. Technol. 51: 185-190.

Nigri F, Oliveira NBN, Bernardo Filho M (2002). Assessment of the effect of Antiseizure Drugs on the Labeling Process of Red Blood cells and Plasma Proteins with Technetium-99m. Cell. Mol. Biol. 48: 793-801.

Phelps ME (2000). Inaugural article: positron emission tomography provides molecular imaging of biological processes. Proc. Natl. Acad. Sci. 97: 9226-9233.

Reymond JM (2007). Development of an instrument for time-activity curve measurements during PET imaging of rodents. Nucl. Instrum.s \& Meth. Phys. Res. A. 571: 358-361.

Rohren EM, Turkingto TG, Coleman RE (2004). Clinical applications of PET in oncology. Radiol. 231: 305-332

Saha GB (2010). Fundamentals of Nuclear Pharmacy. 6th ed, New York: Springer-Verlag.

Santos-Oliveira R, Machado M (2011). Pitfalls with radiopharmaceuticals. Am. J. Med. Sci. 342: 50-3.

Souza DE, Pereira MO, Bernardo LC, Carmo FS, Fonseca AS, Bernardo-Filho M (2011). An Experimental Model to Study the effects of a senna extract on the blood constituent labeling and biodistribution of a radiopharmaceutical in rats. Clinics 66: 483-486.

Simões CM, Schenkel EP, Gosmam G, Mello JCP, Mentz LA, Petrvick PR (2007). In review in Portuguese. $5^{\text {th }}$ ed., Farmacognosia: Da planta ao medicamento. Rio Grande do Sul, Brazil: Universidade/UFRGS/Edda/EFSC. 49-108.

Steenkamp V, Nkwane O, Van Tonder J, Dinsmore A, Gulimian M (2013). Evaluation of the phenolic and flavonoid contents and radical scavenging activity of three southern African medicinal plants. Afr. J. Pharm. Pharmacol. 7 (13): 703-709.

Velasques de Oliveira SM, Julião LMQO, Souza WO, Mesquita SA, Santos MS (2010a) Methodology for radionuclides quantitative "in vitro" bioassay. Cell. Mol. Biol. 56: 41-43.

Velasques de Oliveira SM, Carneiro JSW, Silva EP, Boasquevisque EB (2010b). Protocol for 18F-FDG Quantification in Pet - Ct wole body exams. Cell. Mol. Biol. 56: 44-46.

Zhang W, Kung MP, Oya S, Hou C, Kung HF (2007). (18) F-labeled styrylpyridines as PET agents for amyloid plaque imaging. Nucl. Med. Biol. 34: 89-97. 